\section{EMBRYARIDDLE}

Aeronautical University

SCHOLARLY COMMONS
Journal of Aviation/Aerospace

Education \& Research

Volume 18

Number 3 JAAER Spring 2009

Article 14

Spring 2009

\title{
Self Defense 101: An Exploration of Self Defense Training and Its Applicability for College Flight Majors
}

Edward John Overchuk

Follow this and additional works at: https://commons.erau.edu/jaaer

\section{Scholarly Commons Citation}

Overchuk, E. J. (2009). Self Defense 101: An Exploration of Self Defense Training and Its Applicability for College Flight Majors. Journal of Aviation/Aerospace Education \& Research, 18(3). https://doi.org/ 10.15394/jaaer.2009.1431

This Article is brought to you for free and open access by the Journals at Scholarly Commons. It has been accepted for inclusion in Journal of Aviation/Aerospace Education \& Research by an authorized administrator of Scholarly Commons. For more information, please contact commons@erau.edu. 


\title{
SELF DEFENSE 101: AN EXPLORATION OF SELF DEFENSE TRAINING AND ITS APPLICABILITY FOR COLLEGE FLIGHT MAJORS
}

\author{
Edward John Overchuk
}

\begin{abstract}
This research explores the feasibility of developing a self defense program for flight majors at a university. Traditional systems of martial arts are discussed and the limitations in these systems are explored. Traditional martial arts have many components found in modernized systems of self defense. The major difference between traditional and modern systems is that traditional ways take years to perfect and may not address situations in the flight environment. Modem systems try to replicate environments where the self defense encounter would occur and attempt to teach the system in the quickest manner possible. Based on the research done by Overchuk (2008), pilots have Multiple Intelligence (MI) profiles which are different from other professions. Multiple intelligences are a preferred way of thinking or an ability a person uses to make sense of a situation. Because pilots have distinct MI profiles, suggestions have been made to change self defense training regimens to fit a pilot's MI profile.
\end{abstract}

According to the Transportation Security Administration (not dated) "The Vision 100 - Century of Aviation Reauthotization Act" requires air carriers providing scheduled passenger air transportation to conduct basic security training for their flight and cabin crewmembers in order to prepare them for potential threat conditions that may occur onboard an aircraft. If self defense training programs are to be incorporated into airline procedures, it may be prudent to prepare college flight students for this type of education. Because training at the airlines and by the TSA is relatively short, typically one or two days, an aviation student might benefit more from a short course if they had previous training in self-defense concepts, theories, and movements. A simple solution would be to have flight majors enroll in self defense courses already offered at the university. Unfortunately, not all martial arts/self defense programs are equal in quality or philosophy. In fact, the self defense training offered at a university (or elsewhere) may be inappropriate and incompatible for the flight environment.

When most people read or hear the words self defense or martial arts, they often equate it with the eastern martial arts (H. B. Armstrong, 2002). The martial arts come in many forms and from many cultures. Some of the traditional and most commonly known in the United States are Kung Fu, Tae Kwon Do, Karate, Kenpo, and Jujutsu. Most of the popularity for these martial arts grew from the movies and recently televised Mixed Martial Arts competitions (MMA). According to legend, the traditional martial arts started in India and then migrated to China (Grapek, 1997; Mitose, 1980; Parker, 1960, 1982). From China, the traditional forms of self defense spread through Japan, Korea, Okinawa, and eventually into the United States.

Kung Fu translates as "skill" or "ability" and can encompass painting and cooking, but it is most commonly associated with the skill of fighting (Corcoran \& Farkas, 1983). There are hundreds of forms of Kung Fu and they can be broken down into groups of fighting skills, health development, and dance. Tae Kwon-Do simply means the art of kicking and punching. The system trains the mind and body with an emphasis on developing moral character. The use of the feet for fighting is the "trademark" and beauty of Tae Kwon-Do. Karate means empty hand and it is an art of 
self defense and sport. Unlike Judo or Jujutsu karate is not a grappling art. The emphasis is to develop the hands, feet, and body to deliver blows to an ageressor. Kenpo stands for "Law of the Fist"(Parker, 1960). Kenpo is stated to be the first "Americanized" martial art (Corcoran \& Farkas, 1983). The emphasis of the art is flexibility of movements which are tailored to the individual not the art (Corcoran \& Farkas, 1983; Parker, 1960, 1982; Parker \& Gow, 1967). Students are encouraged to alter the moments to fit their needs, but not the underlying principle of the self defense technique. Kenpo utilizes elbows, knees, kicks and punches through both circular and linear movements. Jujutsu is literally the art of suppleness (Corcoran \& Farkas, 1983). Its self defense techniques were developed for effectiveness in combat, which included weapons such as the sword. Jujutsu uses grappling, throws, punches, kicks, and joint locks. If an aviation student had an interest in training in the traditional forms of self defense, they would most likely develop the basic movements used in nearly all self defense techniques. The only question/caution would be, how effective would this knowledge be in an aviation environment.

Traditional martial arts (non-sport) techniques were practiced as weapons arts and were designed to kill, maim, and break bones (Draeger, 1982; Murray, 2006). Some aspects of the martial arts are used for personal growth and developmental reasons (Overchuk, 2002, 2005). With the mass introduction of children into the martial arts, the arts have evolved into family and sport activities emphasizing the beauty of form and competition. In the fighting arts literature, there are questions being asked on whether the martial arts are truly "War (martial) Arts." (Draeger, 1982; Rosenbaum, 2006) According to these tacticians, years of evolution and modification has altered the martial arts causing them to lose most of their combative application. In other words, they have become more sport and family oriented. This training could give a false sense of security to the aviation student if he/she was not aware of the limitations found in sport martial arts.

Because human aggressive behavior can vary from simple non-conpliance to extreme violence (Bor, 2007; King, 1999) certain martial arts training may not meet the needs of a flight crew. Therefore, a course in self defense needs to be developed/chosen which emphasizes the necessities of the flight crew and the environment where they find themselves (Williamson, 2003). Military psychologists and law enforcement trainers have recognized the need for modification in combative training and protective techniques (Grossman, 1996; Murray, 2006).

According to Williamson (2003), a flight crew self- defense program should take into account the environment where the flight crews find themselves. The defensive system should involve striking, grappling, and weapons techniques all within a realistic environment. What Williamson is describing is what some martial tacticians describe as "reality based training"(Murray, 2006; Quinn, 1996; Siddle, 2001), Realistic based training (RBT) prepares law enforcement professionals for the types of encounters they will experience on the job (Faulkner \& Danaher, 1997). From the Author's perspective, the self defense techniques in reality based training are similar to the ones found in the traditional system of self defense. Basically, there are only so many ways a person can punch, kick, grab, throw, and counter an aggressive attack. Many times "advanced self defense techniques" are combinations and variation of the basic self-defense movements. As Faulkner \& Danaher (1997) have stated in their publication, there are no "magic bullets" to controlling a subject. Therefore, even if an aviation student engages in either traditional forms of self defense or self defense designed for flight crews, they should understand that not all techniques or ageressive encounters will have perfect solutions or endings.

The difference between traditional self defense training and reality based training is the way the technique is taught to the person, the environment where it is taught, and the introduction of the adrenaline stress response during the application/practice of the self defense technique. Self defense techniques in RBT emphasize gross motor movements and they are performed at futl power and full speed on a well protected and padded person (Quinn, 1996). Striking at a well protected person who moves unpredictably is a better simulation of reality than hitting a punching bag or pad. High power strikes are delivered to the head, neck, abdomen, and groin. The fight continues "unabated" and to the ground if necessary. When it is clear the aggressor is thwarted, the fight is discontinued. Reality Based Training seems very beneficial to flight students or pilots especially for short term training. An unpredictable padded aggressor (as opposed to a static punch or striking pad) will quickly expose the student to their strengths and limitations, as well as, to what works and what does not work.

Not all martial arts training for pilots will be equally effective, so training in an environment that is unique to a flight crew is essential. Mobility is limited because of the many obstacles in the cramped spaces of the cockpit and cabin. Therefore, fancy, complicated, jumping and spinning techniques will not be effective (Williamson, 2003). These complex and fine motor skill movements are further hindered by the adrenaline stress response during an 
altercation (Grossman, 2007; Murray, 2006; Quinn, 1996; Siddle, 2001). Because of the changing blood chemistry during an altercation, gross motor skills should be emphasized for short-term self defense programs. Gross motor skills utilize the large muscle groups, like the legs and arms, which are used for pushing and pulling (Siddle, 2001).

It is also important to train pilots in situations that approximate the emotional reactions that thoy may face from a real threat. The simulation of real attacks in RBT induces an adrenaline stress response which is important for a number of reasons. In high stress environments, higher cognitive functions diminish, fine motor skills are lost, perceptual tunneling occurs, and auditory exclusion takes over (Grossman, 2007; Murray, 2006). Therefore, complicated self defense techniques are sometimes rendered ineffective. Using simple gross motor self-defense movements in a stress inducing environment conditions the person to be able to use the technique in combative situations (Quinn, 1996). The recall of the defensive technique is also less hindered because higher cognitive functions are not needed to perform gross motor movements.

Another system of RBT self defense worth mentioning is natural movement or reflexive movement self defense. The system uses the human's natural movement and the natural defensive system which is hard wired into the body (AOTS, 2003), It is known as the S.P.E.A.R. SYSTEMTM, which means Spottaneous Protection Enabling Accelerated Response (Blauer, n.d.). This self protective system is a "behaviorally researched, close quarter personal defense method that utilizes the body's natural flinches and reactions to fear or violence and then converts these reactions into efficient tactical choices. According to Blauer, the system is "Genetically wired and behaviorally inspired ${ }^{\mathrm{TM}}$, Therefore, anyone can apply the system." Blauer's concept about "anyone can apply it" is important for pilots, because some may be reluctant to train for any prolonged period.

The Transportation Security Administration(TSA) has also developed a voluntary self defense program for flight crews. Crew Member Self Defense Training (CMSDT) is available to any active flight or cabin crew member (Transportation Security Administration, n.d.). The program has two parts. The crewmember first receives a "self-paced, interactive DVD" and manual to familiarize the person with the basic self defense concepts and techniques. After completing the review there is a short written assessment. The second part of CMSDT is where crewmembers attend a one-day "hands-on" self defense training session at a participating community college. The major drawback to the program is college flight students canthot attend the program because it is for currently enployed flight crewmembers. The exclusion of flight majors to the TSA's training program is a strong reason why a self defense program geared for flight majors is important.

Developing a college Flight Major Self Defense Course (FMSDC) is not beyond the scope of a University's flight program. There is documentation of course requirements mandated by law (see Tables $1 \& 2$ ) and elements the TSA must include in an advanced voluntary crewmember training program (Government Accountability Office, 2005). The FMSDC would not be designed to replace the TSA's CMSDT program, but would be developed to prepare students for such training. Based on the author's 27 years of self defense training and teaching both personal and college level self protective courses, it is his belief that the two days of training by the TSA is far better than no training. However, if the TSA's training or an airlines training program was augmented by a one credit hour course at the college level, it would give flight students a major advantage in retaining and being able to apply protective measures in high stress threatening environments. The selfdefense course could fit into an aviation students schedule as an elective.

In order to perform a self defense technique in a real situation the author calls this ability Tactical Application (Overchuk, 2005) In Overchuk (2005) "applying the combative techniques requires one to have speed, to have mastered the physical movements to perform the technique, and to have attained the tactical knowledge to execute the procedure." (p.101). Ericsson (1996) states that developing this level of expertise takes up to 10 years of practice. Based on the author's observations and communications with airline personnel, most crewmenbers are not going to train for 10 years in a self defense program. Therefore, a college self defense course for flight majors will have advantages. Students would have a strong foundation on which develop new techniques and strategies established by the TSA or an airline.

Twenty five hours of defensive training seents to be a good starting point for a college Flight Major Self Defense Course (FMSDC). As an instructor and participant observer in Kent State's self defense program (25 hours over 5 weeks), the author has made some note worthy observations. The self defense course consisted of lectures during class, the use of striking pads for punching and kicking, the application of fine (complex) and gross (simple) motor movements, and applying self defense techniques on 
each other. After 10 hours (two weeks) of self defense training, students start developing defensive movements that would have some impact on an assailant. When surprised and asked to execute a self defensive movement, most use gross motor movements like a punch, paim or knee. The techniques look somewhat awkward. \$orne students miss obvious striking points on the assailant, and they often choose an incorrect movement based on distance from the attacker. At this level, students have expressed that elbows, punches, knees and forward moving kicks (snap kick) feel most comfortable to execute. The author has also noticed that simple garment grabbing of an opponent is a very natural movement at this level.

Around 20 hours of training, students do a fairly accurate job of executing prescribed self defense movements. The student can pick out targets on the opponent and begin adjusting their distance, so the strike will make impact on the aggressor. Toward the end of the $5^{\text {th }}$ week of training, students were able to break free from prescribed defensive movements and started to execute combinations not taught in class routines or self defense movements. In other words, a student could develop their own combination of movements to meet the needs of the attack. During the five week course, the author observed obvious differences in strength, power, and mindset between the students. At this point, it is unknown if the students could actually defend themselves in a life or death situation. This is a similar observation made of the TSA program in a Report to Congressional Requesters (Government Accountability Office, 2005).

In addition to selecting the proper type and length of training, it is important to recognize that all humans/students have differing athletic and intellectual abilities. When developing a self defense course for flight students, it may be advantageous to teach the course material according to a pilot's intelligence profile. Gardner (1999) defines intelligence as, "a biopsychological potential to process information that can be activated in a cultural setting to solve problems or create products that are of value in a culture" (p. 34). Gardner's theory came from his investigations of "cognitive and developmental psychology, differential psychology, neuroscience, anthropology, and cultural studies" (Gardner \& Moran, 2006, p. 227). Initially, he suggested the existence of seven intelligences (Gardner, 1983). In 1999, he increased the number to eight distinct intelligences: Linguistic, Logical-mathematical, Spatial, Kinesthetic, Musical, Naturalist, Interpersonal and Intrapersonal (Gardner, 1999).

Gardner's definition of intelligence incorporates easily into aeronautical terms. Pilots are part of a unique culture (commercial aviation and aviation as whole), and they must continually process information to solve novel problems. A pilot must also deliver a service (product) that is reliable, yet maintain a balance between safe operations and reliability. These pilot potentials are highly valued by society and the flying public

Overchuk (2008) found acronautics students and professional pilots were found to have similar multiple intelligence $(\mathrm{MI})$ profiles. The pilot MI profile is distinctly different from profiles found in educators, business consultants, and lawyers. As measured by the Multiple Intelligence Developmental Assessment Scale (MIDAS), both Professional Pilots and Student Pilots scored high on Spatial Intelligence and Intrapersonal Intelligence respectively (See tables $3 \&$ \&). Professional Pilots mean scores on Spatial Intelligence was $66.07(\mathrm{SD}=11.8)$ and a mean of $65.69(\mathrm{SD}=11.76)$ on Intrapersontal Intelligence. Student pilot mean scores on Spatial Intelligence was 63,66 $(\mathrm{SD}=13.6)$ and a mean score of $63.33(\mathrm{SD}=9.88)$ on Intrapersonal Intelligence.

Spatial intelligence is the ability to think in pictures and images. Individuals with this intelligence can transform and recreate different aspects of the visual-spatial world through mental imagery. Intrapersonal intelligence is the capacity to think about thinking. Essential functions of this intelligence include goal-setting, self-appraisal, selfmonitoring/correction and emotional self-management (Shearer, 2004). Introspection and self-regulation are key features of this intellect. Understanding the students' MI profiles can help instructors gage how training should be implemented.

When developing a self defense program based on a pilot's MI profile, the techniques should be taught in a way where a pilot can utilize his/her strong points such as mental inagery. The FMSDC could allow the creation of scenarios and self-defense techniques where pilots could practice through mental imagery. Mental inagery has been known to increase athletic performance (Hall, 2001). After practicing the technique mentally or visually, it could then be applied to training situations and people. This would correct false images and ingrain new pictures of how the technique must be delivered.

Because pilots have scored high on Intrapersonal Intelligence, the FMSDC should incorporate ways to set goals, to use self-appraisal, to self-monitor/correct and to hone in on enotional self-managenent. In a crisis situation, emotional self-management is a key element in addressing hostile situations (Overchuk, 2005). 
Student pilots scored higher than professional pilots on Body-Kinesthetic intelligence. Body-Kinesthetic intelligence is an expertise in using one's whole body to express feelings, ideas, and to manipulate objects in goal directed behaviors (T. Armstrong, 2000; Shearer, 2004). The difference in groups could be a result of age. The mean age for professional pilots in the author's 2008 study was 42.6 $(S D=10.6)$, where the student pilot's mean age was 21.5 $(\mathrm{SD}=3.4)$. From these results, it may indicate that older pilots may need a different training regimen or at least a modification to fit the lower emphasis on body kinesthetic intelligence. On the other hand, to help better prepare older pilots for defensive situations, more emphasis could be placed on body movements, so these skills can be improved.

Overall, the author suggests that much research is needed into what makes a good self defense technique or self defense program for pilots. The author further suggests that some training is better than none, which is contrary to some traditional martial artists (Funakoshi, 1975). Because people vary in attitude, physical ability, and mental fortitude, a "one size fits all" self defense program may be impossible to develop. From the author's personal observations and experiences, practice is one of the major components that makes one person superior to another in the martial arts or a self defense program. In the perfect situation, the pilots will be barricaded in the cockpit. However, pilots may find themselves in the passenger cabin where they may be called upon as an additional crewmember to help in a hostile situation. Therefore, self defense for pilots should not be overlooked.t

Edward John Overchuk graduated fiom Baldwin Wallace College with a BA in Psychology. He attained a Master of Arts Degree from John Carroll University in Counseling. On June 30, 2002, the author received a Ph.D. in Clinical Psychology from the Union Institute \& University in Cincinnati, Ohio. His academic research involved the martial arts and psychology. He is presently an assistant professor at Kent State University in the Division of Aeronautics. Ed teaches both aviation and self defense classes at the university. He is a former captain for US Airways Express/PSA, holds an Airline Transport Pilots license, and has Flight Instructor Certificates for both airplanes and helicopters. Ed currently holds a 6 th Degree Black Belt in Traditional Kenpo Karate, he is a Certified Master Instructor and has 27 years of teaching and training experience in various self defense systems.

1. 


\section{References}

AOTS. (2003). Flight crew defense readiness: AOTS MultiMedea Productions.

Armstrong, H. B. (2002). Perception \& reality, Hop-Lite; Newsletter of the International Hoplology Society, Winter(12), 1.

Armstrong, T. (2000). Multiple intelligences in the classroom (2nd ed.). Alexandria: Association for Supervision and Curriculum Development.

Blauer, T. (n.d.). S.P.E.A.R. System. Retrieved August 2008, from http://www.tonyblauer.com/4 105/02_01_01_spearsystem.asp

Bor, R. (2007). Psychological factors in passenger and crew behavior: A clinical overview [Electronic Version]. Travel Medicine and Infectious Disease, 5, 207-216. Retrieved 2008 from www.sciencedirect.com.

Corcoran, J., \& Farkas, E, (1983), Martial Arts: Traditions, history, people. New York: Gallery Books.

Draeger, D. F. (1982). The martial-civil dichotomy in asian combatives. Hoplos: The Journal of the International Hoplology Society, 3(1), 6-8.

Exicsson, K. A. (1996). The acquisition of expert performance: An introduction to some of the issues. In K. A. Ericsson (Ed.), The road to excellence: The acquisition of expert performance in the arts and sciences, sport, and games (pp. 1-50). Mahwah, NJ: Erlaum.

Faulkner, S. D., \& Danaher, L. P. (1997). Controlling subjects: Realisțic training vs. Magic bullets [Electronic Version]. FBI Publications: law enforcement bulletin. Retrieved 2008 from http:/www.fbi.gov/publications/leb/1997/feb974.htp.

Funakoshi, G. (1975), Karate-do: My way of life. New York: Kodansha.

Gardner, H. (1983). Frames of the mind: The theory of multiple intelligence. New York: Basic Books.

Gardmer, H. (1999). Intelligence refromed. New York: Basic Books.

Gardner, H., \& Moran, S. (2006), The Science of Multiple Intelligences Theory: A Response to Lynn Waterhouse. Educational Psychologist, 4I(4), 227-232.

Government Accountability Office. (2005). Aviation security: Flight and cabin crewmember security training strengthened, but better planning and internal controls needed [Electronic Version]. Report to Congressional Requesters, 1-46. Retrieved 2008 from http://www.gao.gov/new.items/d05781.pdf.

Grapek, J. (Writer) (1997). The secrets of the warrior's power. Kung Fu the fighting arts of china: Winstar Home Video

Grossman, D. (1996). On killing. New York: Back Bay Books.

Grossman, D. (2007). On combat: The psychology and physiology of deadly conflict in war and in peace (2 ed.). Millstadt: PPCT Research Publications.

Hall, C. R. (2001). Imagery in spot and exercise. In R. N. Singer, H. A. Hausenblas \& C. M. Jathelle (Eds.), Handbook of sport psychology (2 ed.). New York: John Wiley \& Șons.

King, R. (1999). Aerospace clinical psychology. Brookfield: Ashgate.

Mitose, J. M. (1980). What is self-defense? (Kenpo jiu-jitsu): California State University. 
Murray, K. R. (2006). Training at the speed of life: The definitive textbook for military and law enforcement reality based training (Vol. 1). Gotha: Armiger Publications.

Overchuk, E. J. (2002). Martial arts psychology: A journey in personal growth and development: Dissertation Abstracts International: Section $B$ : The Sciences and Engineering.

Overchuk, E. J. (2005). Martial arts psychology: A journey in personal growth and development (Vol. 1). Valley View: National Institute of Martial Arts and Sciences.

Overchuk, E. J. (2008). Aeronautical decision making and the function of multiple intelligence in pilots. Paper presented at the Midwest Decision Sciences Institute 2008 Conference Erie Pennsylvania.

Parker, E. (1960). Kenpo karate: Law of the fist and empty hand. Los Angeles: Delsby Publications.

Parker, E. (1982). Infinite insights into kenpo: Mental stimulation (Vol. 1). Los Angeles: Delsby Publications.

Parker, E., \& Gow, T. (1967). Kenpo karate; Fully illustrated (Vol. 1 The Basics). Pasadena: Kenpo Karate Studios.

Quinn, P. (1996). Real fighting: Adrenaline stress conditioning through scenario-based training. Bouldert: Paladin Press.

Rosenbaum, M. J. (2006). The range: Empty-hand to weapons; Civilian to martial. Hop-Lite: Newsletter of the International Hoplology Society, Spring(15), 1-2.

Shearer, B. (2004), Using a multiple intelligences assessment to promote teacher development and student achievement. Teachers College Record, 106(1), 147-162.

Siddle, B. K. (2001). Sharpening the warrior's edge: The psychology \& science of training. Millstadt: PPCT Research Publications.

Transportation Security Administration, (th.d.). Crew Member Self Defentse Training Program [Electronic Version]. Retrieved 2008 from http://www.tsa_gov/lawenforcement/programs/self_defense_cmsd_programs.shtm

Williamson, H. (2003). Choosing a self-defense training program [Electronic Version]. Airline pilot, October, 30. Retrieved August $2008 \mathrm{from}$ http://www.alpa.org/alpa/DesktopModules/ViewDocuments.aspx?DocumentID=5393. 


\section{Appendix}

Table 1 ligts the minimum training elements required by law, as enacted by ATSA and as amended by Vision 100, for basic crew member security training.

Table 1: List of Basic Crew Member Becurity Training Elements Required By Law

\begin{tabular}{|c|c|c|}
\hline Leglelative requiremente for crow mombar mecurity träning & ATSA & VIsion 100 \\
\hline Determinatlon of the seriousness of any occurrence & $\cdot$ & $\because$ \\
\hline Crew communication and coordination & $\cdot$ & $\cdot$ \\
\hline Approprate responses to detend oneself & - & $\bar{*}$ \\
\hline Use of protective devices essigned to crew members & $\cdot$ & $\cdot$ \\
\hline $\begin{array}{l}\text { Psychology of terrorists to cope with hijacker behavlor and } \\
\text { passenger responses }\end{array}$ & $\cdot$ & $\overline{-}$ \\
\hline $\begin{array}{l}\text { (Live) situational training exercises regarding various threat } \\
\text { conditions }\end{array}$ & $\cdot$ & $\overline{1}$ \\
\hline Flight deck procedures or aircraft maneuvers to delend the aircraft & $\cdot$ & $\cdot$ \\
\hline Recognizing suspicious activities & & $\cdot$ \\
\hline The proper commands to give passengers and attackers & & $\cdot$ \\
\hline $\begin{array}{l}\text { The proper conduct of a cabin search, including explosive device } \\
\text { recognition }\end{array}$ & & $\cdot$ \\
\hline
\end{tabular}

Soures: ATSA and Veron 100.

Table 2 lists the training elements that TSA must include in an advanced voluntary self-defense training program for flight and cabin crew members under the law, as amended by Vision 100.

Tabjo 2; List of Advanced Voluntary Crew Momber Self-Dofonse Training E्llements Aequired By Law

\begin{tabular}{l} 
Legielatuve requirements tor crew membar security training \\
Deterring a passenger who might present a threat \\
\hline Advanced control, strking, and restraint techniques \\
\hline Training to defend onesefi against edged or contect weapons \\
Methods to subdug and retstrain an attacker \\
Use of available items aboard the alrcraft tor self-defense \\
Appropinate and effective responses to defend oneself including the use of force against \\
an attacker
\end{tabular}

Bauks: Vition iod. 
Table 3

Student Pilot Main Scale Descriptve Statigtics

\begin{tabular}{|c|c|c|c|}
\hline & $\mathrm{N}$ & Mean & Std. Deviation \\
\hline Spatial & 55 & 63.66 & 13.632 \\
Intrapersonal & 55 & 63.33 & 9.885 \\
Interpersonal & 55 & 59.71 & 12.287 \\
Kinesthetic & 55 & 57.65 & 12.862 \\
Logical & 55 & 56.82 & 14.337 \\
Naturalist & 55 & 54.32 & 15.482 \\
Linguist & 55 & 51.58 & 14.605 \\
Musical & 55 & 45.06 & 17.537 \\
Valid N & 55 & & \\
\hline
\end{tabular}

Table 4

Professional Pllot Main Scale Descriptive Statistice

\begin{tabular}{|l|r|r|r|}
\hline & $N$ & Mean & \multicolumn{1}{|c|}{ Std. Deviation } \\
\hline Spatial & 31 & 66.07 & 11.800 \\
Intrapersonal & 31 & 65.69 & 11.768 \\
Logical & 31 & 61.93 & 13.586 \\
Naturalist & 31 & 52.05 & 12.845 \\
Interpersonal & 31 & 51.04 & 17.680 \\
Linguist & 31 & 50.15 & 14.794 \\
Kinesthetic & 31 & 45.71 & 11.672 \\
Musical & 31 & 38.57 & 20.792 \\
Valid N & 31 & & \\
\hline
\end{tabular}


